\title{
Proportional assist ventilation as an aid to exercise training in severe chronic obstructive pulmonary disease
}

\author{
P Hawkins, L C Johnson, D Nikoletou, C-H Hamnegård, R Sherwood, M I Polkey, \\ J Moxham
}

Thorax 2002;57:853-859

See end of article for authors' affiliations

Correspondence to:

Dr P Hawkins, Department

of Respiratory Medicine \&

Allergy, King's College

Hospital, Bessemer Road, London SE5 9PJ, UK;

drpeterhawkins@

yahoo.co.uk

Revised version received 23 April 2002

Accepted for publication

24 April 2002

\begin{abstract}
Background: The effects of providing ventilatory assistance to patients with severe chronic obstructive pulmonary disease (COPD) during a high intensity outpatient cycle exercise programme were examined.

Methods: Nineteen patients (17 men) with severe COPD (mean (SD) forced expiratory volume in 1 second $\left(\mathrm{FEV}_{1}\right) 27$ (7)\% predicted) underwent a 6 week supervised outpatient cycle exercise programme. Ten patients were randomised to exercise with ventilatory assistance using proportional assist ventilation (PAV) and nine (two women) to exercise unaided. Before and after training patients performed a maximal symptom limited incremental cycle test to determine peak work rate (Wpeak) followed by a constant work rate (CWR) test at 70\% of Wpeak achieved in the baseline incremental test. Minute ventilation $(\mathrm{VE})$, heart rate, and arterialised venous plasma lactate concentration [ $\left.\mathrm{La}^{+}\right]$were measured before and after each test.

Results: Mean training intensity (Wt/Wpeak) at 6 weeks was $15.2 \%(95 \% \mathrm{Cl} 3.2$ to 27.1$)$ higher in the group that used ventilatory assistance $(p=0.016)$. Peak work rate after training was $18.4 \% 195 \%$ $\mathrm{Cl} 6.4$ to 30.5) higher $(\mathrm{p}=0.005)$ in the assisted group $(\mathrm{p}=0.09)$. [ $\left.\mathrm{La}^{+}\right]$at an identical workload after training was reduced by $30 \%(95 \% \mathrm{Cl} 16$ to 44$)$ in the assisted group ( $p=0.002$ compared with baseline) and by $11 \%(95 \% \mathrm{Cl}-7$ to 31$)$ ( $p=0.08$ compared with baseline) in the unassisted group (mean difference $18.4 \%(95 \% \mathrm{Cl} 3.3$ to 40$), p=0.09)$. A significant inverse relationship was found between reduction in plasma lactate concentration $(\Delta \mathrm{L})$ at an equivalent workload after training during the CWR test and $\mathrm{Wt} / \mathrm{W}$ peak achieved during the last week of training $(r=-0.7, p=0.0006)$.

Conclusions: PAV enables a higher intensity of training in patients with severe COPD, leading to greater improvements in maximum exercise capacity with evidence of true physiological adaptation.
\end{abstract}

$\mathrm{E}$ xercise limitation is a major symptom of patients with severe chronic obstructive pulmonary disease (COPD). ${ }^{1}$ Reduced ventilatory capacity combined with an increased ventilatory load leads to intolerable dyspnoea at low levels of exercise. ${ }^{2}$ Avoidance of dyspnoea and, hence, exercise produces progressive deconditioning in the lower limb muscles indicated by reduced capillary density, mitochondria, and oxidative enzymes. ${ }^{3}$ Exercise involving such muscle groups produces an early and steeper rise in plasma lactate concentration leading to an increased ventilatory load. ${ }^{4}$

Pulmonary rehabilitation programmes have been shown to improve exercise tolerance and quality of life in patients with COPD. ${ }^{56}$ Exercise training is considered an essential component of such programmes but the optimal training strategy for patients with severe COPD is not known. Patients with moderate COPD derive a greater physiological benefit if exercise is performed at a work rate which exceeds their anaerobic threshold. ${ }^{7}$ However, patients with severe COPD are unable to exercise sufficiently to produce a true physiological training effect because of ventilatory limitation. ${ }^{8}$

The application of inspiratory pressure support (IPS) during exercise increases endurance, ${ }^{9}$ reduces dyspnoea, ${ }^{10}$ unloads the respiratory muscles, ${ }^{11}$ and prolongs exercise induced lactataemia. ${ }^{12}$ Proportional assist ventilation (PAV), a mode of ventilation that matches ventilator output to patient effort, ${ }^{13}$ is more tolerable for patients with COPD $^{14}$ and is as effective at prolonging exercise as conventional IPS. ${ }^{15}$ We hypothesised that the application of PAV during an exercise programme would enable patients to achieve higher training work rates and that this would lead to greater improvements in exercise performance. An additional hypothesis was that the mechanism of improvement would be a true physiological training effect, demonstrated by a reduced plasma lactate concentration at a given workload after training.

\section{METHODS}

Patient recruitment

Patients with severe COPD attending the respiratory medicine clinics at King's College Hospital were recruited for the study over a 2 year period. Each patient was either a current smoker or had a history of smoking. Patients with orthopaedic or cardiovascular contraindications to exercise were excluded. The study protocol was approved by the hospital ethics committee and all participants gave informed written consent.

\section{Exercise regimen}

Patients participated in a programme of exercise on a calibrated cycle ergometer. Exercise sessions were held three times per week for 6 weeks. Exercise duration was 30 minutes, although initially many patients were unable to cycle continuously for this length of time. Each session was supervised by one of the authors ( $\mathrm{PH}$ or $\mathrm{DN}$ ) who vigorously encouraged the patients to reach the intensity and duration targets. Initial intensity targets were set at $70 \%$ of the peak work rate observed in the pretraining incremental exercise test. The work rate was increased progressively during the 6 week training period in a standardised manner. This was achieved by increasing the work rate by 5 watts once the subject was able to maintain the existing work rate for 30 minutes. In patients who were unable to cycle continuously at the initial work rate, short rest periods were allowed. Breathlessness and leg fatigue were assessed during the training sessions using a modified Borg score. ${ }^{16}$ Patients were strongly 
encouraged not to stop until a symptom rating of 5 (severe) or more was achieved. During the exercise sessions, heart rate and arterial oxygen saturation, measured by pulse oximetry, were recorded continuously. For patients requiring supplemental oxygen (two unassisted, one PAV), oxygen was delivered by nasal cannulae at a sufficient rate to keep the fingertip oxygen saturation at $90 \%$ or above.

Patients were randomised using sealed envelopes containing the training modality to train with ventilatory assistance or unassisted. Ventilatory assistance was delivered using a BiPAP Vision in PAV mode (Respironics, Murrayville, Pensylvania, USA) applied via a tightly fitting full face mask (Respironics). PAV was set individually for each patient using a method described previously. ${ }^{17}$ First volume assist (VA), with flow assist (FA) set at $1 \mathrm{~cm} \mathrm{H}_{2} \mathrm{O} / \mathrm{l} / \mathrm{s}$ was set by increasing the level of assist by $2 \mathrm{~cm} \mathrm{H} \mathrm{H}_{2} \mathrm{O} / \mathrm{l}$ until "run away" was demonstrated. Then FA, with VA set at $2 \mathrm{~cm} \mathrm{H}_{2} \mathrm{O} / \mathrm{l}$, was set by increasing FA by $1 \mathrm{~cm} \mathrm{H} \mathrm{H}_{2} \mathrm{O} / \mathrm{l} / \mathrm{s}$ until "run away" occurred. $80 \%$ of these values were used initially, with FA and VA settings adjusted for patient comfort to avoid "run away" during exercise. Mean (SD) values were $3.6(0.7) \mathrm{cm} \mathrm{H}_{2} \mathrm{O} / \mathrm{l} / \mathrm{s}$ and 12.7 (1.5) $\mathrm{cm} \mathrm{H}_{2} \mathrm{O} / \mathrm{l}$ for FA and VA, respectively.

No educational component was included in the programme and patients were discouraged from doing extra exercise beyond their normal activities at home.

\section{Outcome measures}

Patients visited the laboratory on two occasions before and two occasions within 1 week of finishing the programme. Testing sessions were performed at the same time of day for each individual patient.

Spirometric tests were performed using a bellows spirometer (Vitalograph, Buckinghamshire, UK). Forced expiratory volume in 1 second $\left(\mathrm{FEV}_{1}\right)$ and vital capacity (VC) were determined from the best of three manoeuvres. The carbon monoxide transfer factor (TLCO) was determined using a single breath method and the results of three manoeuvres were averaged. Lung volumes were measured using a body plethysmograph (Morgan Medical Ltd, Kent, UK). The results were compared with the normal values recommended by the European Respiratory Society. ${ }^{18}$

Exercise testing was performed on an electromagnetically braked cycle ergometer (Tunturi, Piispanritsi, Finland). Patients breathed through a two way non-rebreathing valve (Hans-Rudolph 2600 series, Kansas, MO, USA) whilst wearing a tightly fitting facemask covering the nose and mouth. A lightweight Lilly pneumotachograph (F300L, GM Instruments, Kilwinning, UK) was attached to the inspiratory limb of the circuit. Flow was recorded continuously with on line integration to provide tidal volume and minute ventilation using a modification of the Labview programme (National Instruments, Austin, TX, USA) developed by one of the authors $(\mathrm{CH})$ running on an Apple PowerMac computer (Apple Computer Inc, Cuopertino, CA, USA). Heart rate was measured from the R-to-R interval of the electrocardiogram recorded from a three lead configuration. Arterial $\mathrm{O}_{2}$ saturation was measured by a pulse oximeter (Model 3700; Omedha, Louisville, CO, USA).

Before exercise testing a 21-gauge butterfly catheter was placed in a vein on the dorsum of the hand or forearm. Heparinised saline was used to keep the catheter patent. The hand was heated to $43^{\circ} \mathrm{C}$ using a water bath. This procedure yields $\mathrm{PCO}_{2}, \mathrm{pH}$, and lactate levels that approximate arterial blood levels. ${ }^{19}$ In three patients (two unassisted, one PAV) we were unable to insert an indwelling venous catheter so a single venous sample was drawn from an antecubital vein 2 minutes after the end of exercise to enable comparisons of plasma lactate concentration. The same blood sampling site was used before and after the programme in all patients.

Patients first performed an incremental exercise test to tolerance. After 3 minutes of sitting on the cycle ergometer, patients pedalled for 3 minutes with no load applied. The work rate was then increased by $5-10 \mathrm{~W} / \mathrm{min}$ while the patients pedalled at $40-50 \mathrm{rpm}$ with the goal that the incremental phase last 5-10 minutes. Arterialised venous blood was sampled at rest, at the end of exercise, and after a further 2 minutes. Wpeak was defined as the highest work rate that was maintained for 1 minute.

After a 45 minute rest period patients performed a constant work rate (CWR) test. The work rate was set at $70 \%$ of Wpeak achieved in the incremental test. After 3 minutes of sitting at rest on the cycle ergometer the work rate was switched to the chosen level. Arterialised venous blood samples were obtained at rest, at the end of exercise, and 2 minutes thereafter. During these tests symptom ratings for dyspnoea and leg fatigue using a modified Borg scale were obtained. Patients were verbally encouraged to make a maximal effort throughout both exercise tests.

After training, identical tests were performed with an additional blood sample drawn at the time when the pretraining test ended (isotime). The maximal duration of the CWR test was set at 30 minutes. For the three patients in whom we were unable to insert an indwelling venous catheter, the post rehabilitation tests were stopped at the same exercise duration tolerated in the pretraining test in order to obtain venous blood samples. Improvements in the CWR test duration could not therefore be assessed in these patients.

Blood samples were collected in heparinised syringes and immediately put in ice. Each sample was then analysed for $\mathrm{pH}$ and $\mathrm{PCO}_{2}$ (Rapidlab 248, Chiron Diagnostics, Essex, UK). The remainder was put in a test tube containing fluoride and oxalate and spun at 3000rpm for 20 minutes at $4^{\circ} \mathrm{C}$. The plasma was frozen for later lactate analysis (Model 2300; YSI, Yellow Springs, OH, USA)

\section{Statistical methods}

Our primary outcome measure was the magnitude of the reduction of $\left[\mathrm{La}^{+}\right]$at an equivalent work rate after training. The study was designed to have a power of 0.8 to detect a $33 \%$ mean reduction in $\left[\mathrm{La}^{+}\right]$at a 0.05 level of significance. These calculations were based on $\left[\mathrm{La}^{+}\right]$achieved by a similar group of patients in an earlier study ${ }^{12}$ and the assumption that at this level of absolute $\left[\mathrm{La}^{+}\right]$a large reduction would be needed to be clinically significant.

Comparisons between responses before and after the training programme were made using paired Student's $t$ tests. Comparisons between the groups were made using unpaired $t$ tests. Mean values are reported with $95 \%$ confidence intervals (95\% CI) unless otherwise stated. The strength of association between variables was tested using Pearson's correlation coefficients. Significance was accepted at the $p<0.05$ level.

\section{RESULTS}

\section{Patient recruitment}

Fifty six patients were referred to the programme of which 34 were eligible. Twenty nine entered the study with 19 completing it. Reasons for not completing the study included exacerbation of underlying disease $(n=4)$, non-compliance with exercise programme $(n=4)$, and non-pulmonary hospitalisation $(n=2)$. Of those not completing the study six were randomised to the unassisted group and four to the assisted group.

\section{Patient characteristics}

The physical characteristics, lung function, and peak exercise capacity of the study patients are presented in table 1 . All 10 patients randomised to the PAV group were men; in the unassisted group there were two women and seven men.

As determined by the pretraining incremental exercise test, exercise capacity (Wpeak) was severely impaired in both groups. Mean Wpeak was 26\% (95\% CI 20 to 31 ) predicted in 
Table 1 Physical characteristics and peak exercise responses before and after training

\begin{tabular}{|c|c|c|c|c|}
\hline & \multicolumn{2}{|c|}{ Assisted $(n=10)$} & \multicolumn{2}{|c|}{ Unassisted $(n=9)$} \\
\hline & Before & After & Before & After \\
\hline Age (years) & $68(9.1)$ & & $66(6.8)$ & \\
\hline Weight $(\mathrm{kg})$ & $77.2(25.5)$ & & $70.3(22.8)$ & \\
\hline Height $(\mathrm{cm})$ & $177.7(6.3)$ & & $169(6)$ & \\
\hline $\mathrm{FEV}_{1}$ (I) & $0.78(0.22)$ & $0.76(0.17)$ & $0.78(0.18)$ & $0.78(0.18)$ \\
\hline $\mathrm{FEV}_{1}(\%$ pred) & $26(7)$ & $24(6)$ & $28(7)$ & $28(9)$ \\
\hline RV/TLC (\%) & $59(15)$ & $61(9)$ & $62(9)$ & $61(8)$ \\
\hline Kco (\% pred) & $51(24)$ & & $55(24)$ & \\
\hline $\mathrm{PaO}_{2}(\mathrm{kPa})$ & $8.1(1.2)$ & $7.6(2)$ & $8.6(0.9)$ & $8.6(0.9)$ \\
\hline $\mathrm{PaCO}_{2}(\mathrm{kPa})$ & $5.8(0.9)$ & $5.8(1.5)$ & $5.6(0.7)$ & $5.5(0.6)$ \\
\hline Peak work rate (W) & $45.6(10.7)$ & $51.7(10.3)^{*}$ & $43.5(12)$ & $57(13.2) \dagger$ \\
\hline Peak VE (I/min) & $24.4(5.8)$ & $24.7(5.9)$ & $26.2(7.7)$ & $27.1(7.7)$ \\
\hline Peak VE (\%MVV) & $92.5(19.6)$ & & $97(25)$ & \\
\hline Breathing reserve & $2.8(5.5)$ & & $1.1(6.1)$ & \\
\hline Peak lactate $(\mathrm{mmol} / \mathrm{l})$ & $2.84(0.54)$ & $3(1.06)$ & $3(1.1)$ & $2.9(0.83)$ \\
\hline Peak heart rate (beats $/ \mathrm{min}$ ) & $117(10.5)$ & $120(10.9)$ & $117(10.9)$ & $120(9.8)$ \\
\hline Peak heart rate ( $\%$ maximum) & $77(8.3)$ & & $76(8)$ & \\
\hline
\end{tabular}

$\mathrm{FEV}_{1}=$ forced expiratory volume in 1 second; $\mathrm{RV}=$ residual volume; $\mathrm{TLC}=$ total lung capacity; $\mathrm{KCO}=$ carbon monoxide transfer coefficient; $\mathrm{PaO}_{2}, \mathrm{PacO}_{2}=\mathrm{arterial}$ oxygen and carbon dioxide tensions; $\mathrm{VE}=$ minute ventilation.

${ }^{*} p<0.001$ compared with before training.

$\dagger p<0.0005$ compared with before training, $p<0.005$ compared with unassisted.

the PAV group and $27 \%$ (95\% CI 21 to 34 ) in the unassisted group. Peak VE averaged 24.41 (95\% CI 20 to 28.8$)$ in the unassisted group and $26.2 \mathrm{l}$ (95\% CI 20.7 to 31.7 ) in the PAV group. As a percentage of maximal voluntary ventilation (MVV) estimated as $\mathrm{FEV}_{1} \times 35,{ }^{20}$ peak VE was $92 \%(95 \%$ CI 80 to 115 ) and $98 \%$ (95\% CI 77 to 108 ) for the unassisted and PAV groups, respectively. Ventilatory reserve (VR), calculated as $\left(\mathrm{FEV}_{1} \times 35\right)-$ peak $\mathrm{VE}_{\mathrm{E}}$ was $2.8 \mathrm{l}(95 \% \mathrm{CI}-1.4$ to 7$)$ for the unassisted group and 1.11 ( $95 \%$ CI -3.2 to 5.4$)$ for the PAV group.

\section{Responses to training}

By the end of the sixth training session the patients in the PAV group were training at a higher work rate than the unassisted group and this difference persisted to the end of the programme. Mean training intensities in watts and as a percentage of Wpeak are shown for both groups in fig 1 . No problems or injuries occurred during the training programme in either group.

Resting lung function tests did not change after the training programme. Mean body weight did not change significantly in either group.

After training, both groups showed an improvement in exercise capacity in the incremental test. Mean Wpeak increased by $14.5 \%$ (95\% CI 8 to 21 ) in the unassisted group and by $32.9 \%$ (95\% CI 22 to 44$)$ in the assisted group ( $\mathrm{p}=0.005$ $v$ unassisted). Peak $V_{E}$, plasma lactate concentration, and heart rate did not increase significantly in either group after training (table 1). The physiological responses to the incremental tests before and after training are summarised in fig 2 and table 2 .

Physiological responses to the constant work rate test are presented in table 3. Mean exercise duration increased from 8.7 minutes (95\% CI 5.3 to 12.1 ) to 17.2 minutes (95\% CI 10.4 to 23.9) $(\mathrm{p}<0.005 v$ baseline) in the PAV group and from 6.9 minutes (95\% CI 4.2 to 9.6 ) to 13 minutes (95\% CI 4.7 to 21.3) $(p<0.05)$ in the unassisted group, but the difference between the groups was not significant $(p=0.3)$. Heart rate was significantly reduced at isotime in both groups compared with baseline but was not statistically different between groups when expressed as percentage change from baseline. Plasma lactate concentration at isotime was reduced by $30 \%$ (95\% CI 16 to 44 ) in the assisted group ( $\mathrm{p}=0.002 v$ baseline) and by $11 \%$ ( $95 \%$ CI -7 to 33 ) in the unassisted group ( $p=0.08$ $v$ baseline). The mean difference in $\Delta \mathrm{L}$ between the groups was $18.4 \%(95 \%$ CI 3.3 to 40$)(\mathrm{p}=0.09)$.
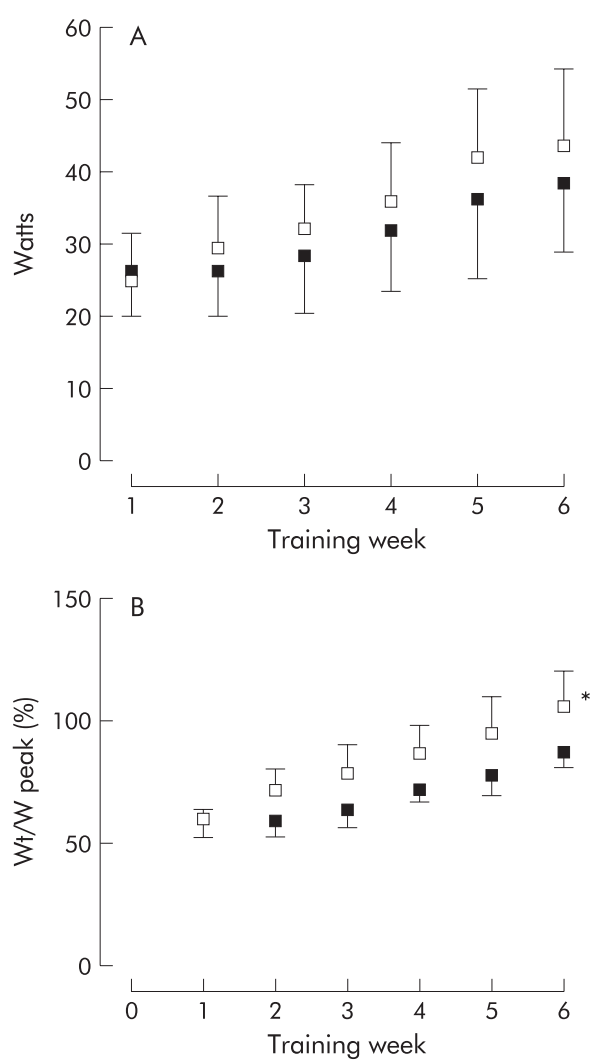

Figure 1 Mean training intensities for both groups in (A) Watts and (B) expressed as a percentage of Wpeak. Error bars refer to standard deviations. ${ }^{*} p=0.016$ (difference $15.5 \%(95 \% \mathrm{Cl} 3.2$ to 27.1).

The ventilatory response to exercise showed a significant reduction in respiratory rate at a given workload for both groups, but there was no statistical difference between the groups. Dyspnoea was significantly reduced at isotime in both groups (fig 3).

The reduction in plasma lactate concentration at a given workload correlated with the increase in Wpeak $(r=-0.61$, $\mathrm{p}=0.0045)$ and with the mean training intensity (Wt/Wpeak) 

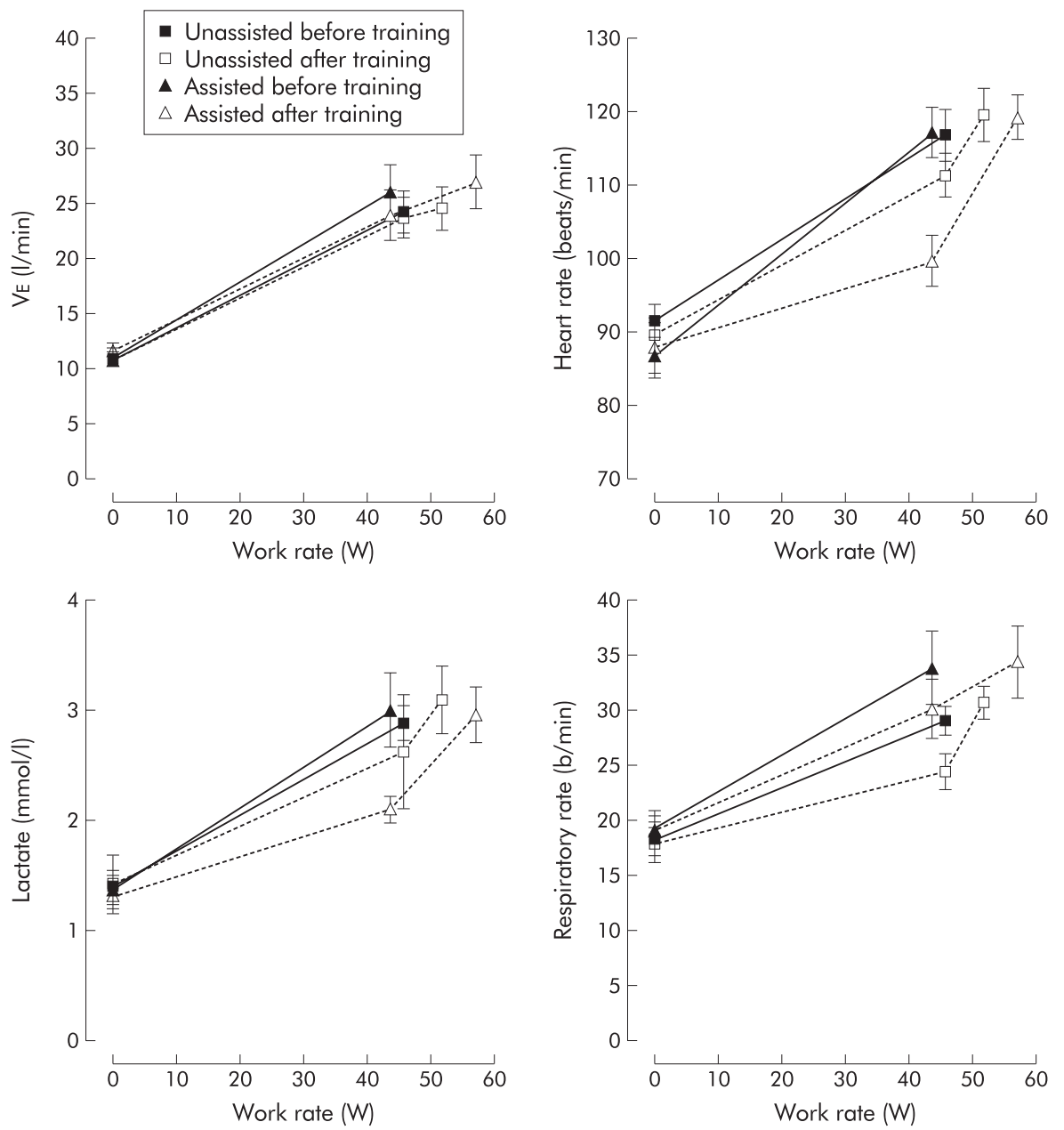

Figure 2 Responses to incremental exercise test before and after training. Error bars refer to SE values.

Table 2 Physiological responses to identical workloads during the incremental test before and after training.

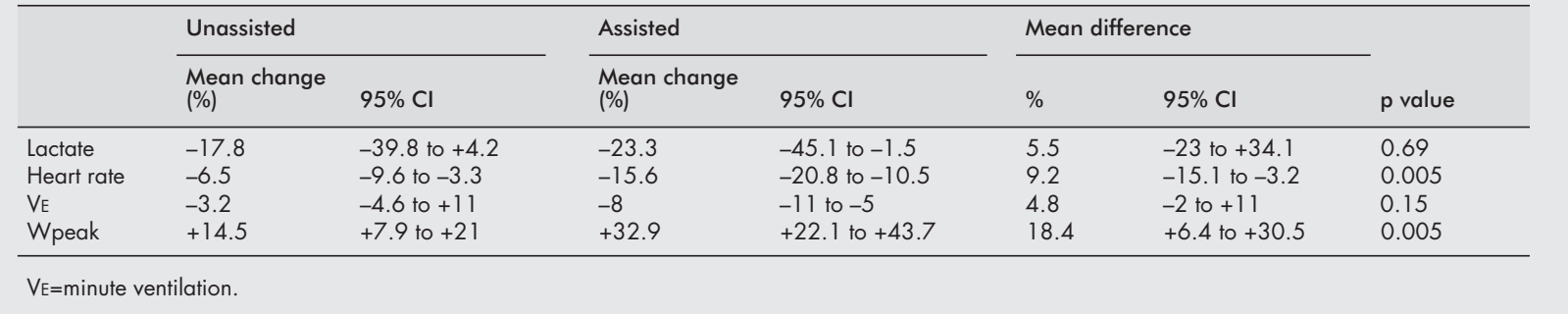

Table 3 Physiological responses to identical workloads during the constant work rate test before and after training

\begin{tabular}{|c|c|c|c|c|c|c|c|}
\hline & \multicolumn{2}{|l|}{ Unassisted } & \multicolumn{2}{|l|}{ Assisted } & \multicolumn{2}{|c|}{ Mean difference } & \multirow[b]{2}{*}{$p$ value } \\
\hline & $\begin{array}{l}\text { Mean change } \\
(\%)\end{array}$ & $95 \% \mathrm{Cl}$ & $\begin{array}{l}\text { Mean change } \\
(\%)\end{array}$ & $95 \% \mathrm{Cl}$ & $\%$ & $95 \% \mathrm{Cl}$ & \\
\hline $\begin{array}{l}\text { Lactate } \\
\text { Heart rate } \\
\text { VE } \\
\text { Duration }\end{array}$ & $\begin{array}{l}-11.6 \\
-6.7 \\
-6.1 \\
+74\end{array}$ & $\begin{array}{l}-30.6 \text { to }+7.4 \\
-12.6 \text { to }-0.8 \\
-9.4 \text { to }-2.8 \\
+36 \text { to }+113\end{array}$ & $\begin{array}{l}-30 \\
-11.8 \\
-6.6 \\
+123\end{array}$ & $\begin{array}{l}-44.3 \text { to }-15.6 \\
-17.5 \text { to }-6.1 \\
-12.6 \text { to }-0.6 \\
+54 \text { to }+193\end{array}$ & $\begin{array}{l}18.4 \\
5.1 \\
0.6 \\
48.9\end{array}$ & $\begin{array}{l}3.3 \text { to } 40 \\
-12.7 \text { to }-2.4 \\
-6.1 \text { to }+7.1 \\
-32 \text { to } 129\end{array}$ & $\begin{array}{l}0.09 \\
0.17 \\
0.88 \\
0.22\end{array}$ \\
\hline
\end{tabular}

achieved during week 6 of the training programme $(r=-0.7$, $\mathrm{p}=0.0006$; fig 4). No significant correlation was found between changes in $\mathrm{VE}_{\mathrm{E}}$ and in plasma lactate concentration. The decrease in plasma lactate concentration produced by training was significantly positively correlated with the peak plasma lactate concentration achieved during the baseline incremental cycle test $\left(\left[\mathrm{La}^{+}\right] \max , r=0.53, \mathrm{p}=0.02\right)$ which is shown in fig 5 . However, this was due to the strong correlation 


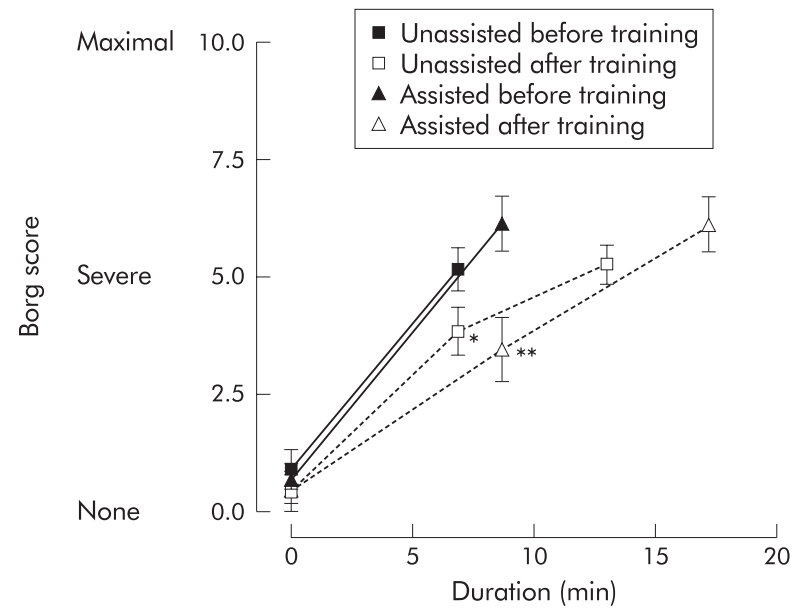

Figure 3 Dyspnoea during the constant work rate test before and after training. ${ }^{*} p=0.04 v$ before training; ${ }^{*} p=0.005 v$ before training. Difference between groups non-significant.
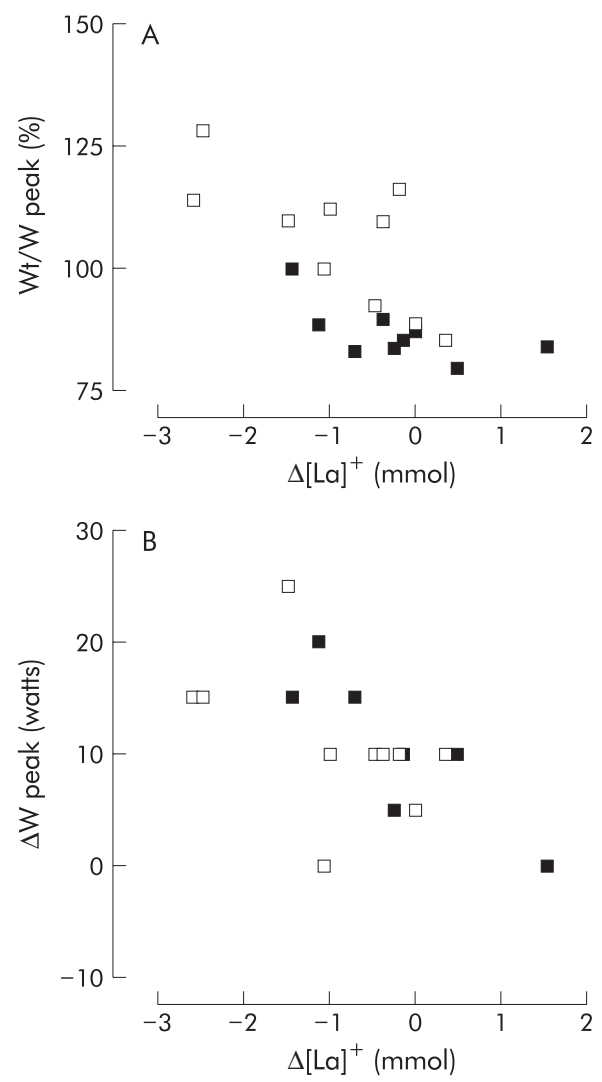

Figure 4 Correlation between the reduction in plasma lactate concentration at an identical workload during (A) the incremental test after training and the training intensity ( $\mathrm{Wt} / \mathrm{W}$ peak) $(r=-0.7$, $p=0.0006)$ and $(B)$ the increase in Wpeak after training $(r=-0.61$, $p=0.0045$ ). Open squares=assisted ventilated; closed squares=unassisted ventilation.

in the assisted group $(r=0.94, \mathrm{p}=0.0002)$ as there was a poor correlation in the unassisted group $(r=-0.56, \mathrm{p}=0.12)$

\section{DISCUSSION}

The main findings of the study are that patients with severe COPD who received ventilatory assistance during an exercise programme achieved greater training intensities and $\Delta$ Wpeak. The main effect of the ventilatory assistance was to increase

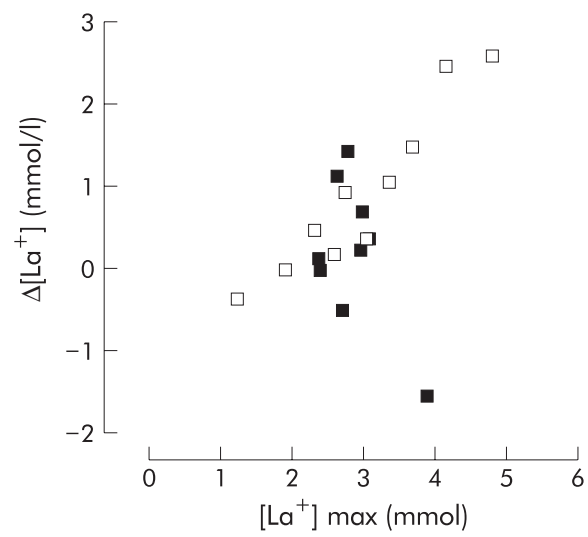

Figure 5 Correlation between peak lactate concentration before training $\left(\left[L^{+}\right] \mathrm{max}\right)$ and decrease in lactate at a given workload after training $(\Delta L)(r=0.53, p=0.002)$. Open squares=assisted ventilation; closed squares=unassisted ventilation.

the training intensity tolerated by the PAV group, which was apparent from the second week and maintained to the end of the programme.

\section{Critique of the methods and characteristics of the groups}

The groups were well matched with respect to lung function and age but there were two women in the unassisted group and none in the assisted group. As randomisation occurred before any assessment of exercise capacity or lung function, it is unlikely that any significant investigator bias was introduced.

The sample size of this study is small and therefore had limited power to detect the small changes in physiological variables such as $V_{E}$, heart rate, or respiratory rate. Although large differences such as $\Delta$ Wpeak and Wt/Wpeak were detected, $\Delta \mathrm{L}$ during the constant work rate test, which was our primary outcome measure, did not achieve significant difference between the two groups $(p=0.09)$. However, there are two reasons to suggest that this may represent a type 2 error. There was a small unexpected overall reduction in $\Delta \mathrm{L}$ in the unassisted group, and the range of $\Delta \mathrm{L}$ in both groups was large; both of these factors reduced the power of the study to identify a fall in $\Delta \mathrm{L}$.

The subjects in this study were not blinded to the intervention that they received and the use of mask ventilation can produce a significant placebo effect. However, there is no convincing way of blinding subjects to this intervention. Other investigators have used "sham" circuits using low levels of CPAP $^{17}$ but our experience is that subjects perform poorly when using such circuits, particularly if they are naïve to mask ventilation. We considered that there would be a significant risk of producing a type 1 error if we used a sham circuit. Although the results of this study could, in part, possibly be explained by a placebo effect of the application of PAV, allowing the patient to achieve greater training intensities, all subjects received the same encouragement and support and we doubt that this was an important factor.

All of the training sessions were supervised by the same two authors ( $\mathrm{PH}$ or $\mathrm{DN}$ ) and, to minimise potential bias, the training regimen used quantitative measures (duration, dyspnoea (Borg score) and work rate) to determine increases in training intensity. It is possible but unlikely that, despite these measures, the investigators may have unknowingly influenced the two groups differently-for example, with respect to verbal encouragement during the sessions. In addition to the training sessions, the assessments before and after training were supervised by the same authors. To minimise potential bias, standardised verbal encouragement was given each 
minute during both the incremental and constant work rate tests. It is acknowledged that this may not completely eliminate bias, especially with regard to outcome measures that are affected by motivation (such as Wpeak and cycle endurance), but it would help to minimise it. Any such bias during the post training assessments would not influence the magnitude of $\Delta\left[\mathrm{La}^{+}\right]$.

\section{Significance of the findings}

Polkey et al found that inspiratory pressure support reduced slowing of oesophageal pressure relaxation rate after exercise in patients with severe COPD, indicating a reduced load on the respiratory muscles. ${ }^{11}$ PAV has been shown to produce greater increases in exercise tolerance in patients with severe COPD. ${ }^{15}$ A reduction in diaphragmatic pressure/time product has been shown in patients with severe COPD using PAV under resting conditions, ${ }^{21}$ and improvements in blood gases have been observed during constant work rate cycle tests. ${ }^{22}$ We therefore hypothesise that PAV unloads the respiratory muscles leading to reduced breathlessness and increased exercise tolerance. This enables patients to place a greater workload on the leg muscles during exercise training sessions, resulting in an increased training stimulus and, hence, training effect. Indeed, when the respiratory muscles are unloaded with a low density gas mixture, a significant skeletal muscle metabolic reserve has been demonstrated..$^{23}$ In fit normal subjects it has been shown that there is competition for blood flow between the legs and the respiratory muscles at high levels of ventilation during cycle exercise..$^{24}$ However, there is evidence to suggest that lower limb oxygen delivery is not compromised in severe COPD. ${ }^{25}$ By reducing the load on the respiratory muscles, PAV could minimise the impact of diminished respiratory muscle blood flow, enabling more intense and prolonged lower limb exercise in patients with severe COPD.

The reduction in plasma lactate concentration (compared to baseline) for a given workload after training in the PAV group suggests that a true physiological training effect was obtained. Although lactic acidosis does not appear to be essential for a training effect to occur, ${ }^{26}$ reductions in plasma lactate concentration at identical workloads indicate a shift in the balance between lactate production and removal in the exercising muscle. ${ }^{27}$ Following cycle training, increased capillary density, mitochondria, and oxidative enzymes occur in the quadriceps of patients with COPD. ${ }^{28}$ This results in a muscle that is more efficient with respect to substrate utilisation and metabolite removal. ${ }^{29}$ The correlation between the reduction in plasma lactate concentration and the increase in Wpeak further supports the view that a true physiological training effect has occurred.

There was a trend for minute ventilation to be reduced in both groups at isotime in the constant workload test but this only reached statistical significance in the unassisted ventilation group. Although a reduction in lactic acid should reduce the ventilatory requirement, there was no correlation between the reduction in lactate and the reduction in minute ventilation. This suggests that the lactate stimulus to ventilation was not significant in this patient group. Recently, a more efficient breathing pattern with a reduced dead space to tidal volume ratio $\left(\mathrm{VD}_{\mathrm{D}} / \mathrm{Vt}\right)$ has been reported after training in patients with severe COPD. ${ }^{8}$ We did not measure end tidal $\mathrm{CO}_{2}$ or calculate $\mathrm{VD} / \mathrm{Vt}$ but respiratory rate was significantly decreased at isotime in both groups, although without an increase in tidal volume.

The values for baseline Wpeak (expressed as a percentage of predicted) are low. ${ }^{30}$ If they were not maximal then Wt/Wpeak would be artificially high. However, the peak plasma lactate concentrations obtained in the incremental cycle test, although modest compared with normal subjects, are comparable to values in other studies of patients with severe COPD. ${ }^{81}$ In addition, the Vemax reported in these patients was close to $100 \%$ predicted MVV, with little ventilatory reserve. These observations, combined with the high dyspnoea ratings reported by patients at the end of the tests $(5-6=$ severe), suggest that the patients in both groups were highly motivated and that the values for Wpeak were probably maximal.

The training intensities achieved by the PAV group were significantly greater than the unassisted group throughout the last 5 weeks of the programme. As the study was not (and could not have been) blinded, it could be argued that bias from the investigators supervising the exercise sessions may have led to more effective encouragement in the PAV group. In a similar group of patients Maltais and co-workers reported a mean training intensity of $66.8 \%$ during the last 4 weeks of a 12 week training programme, ${ }^{31}$ and the training work rates in the unassisted group of the present study compare favourably with Maltais' results. Casaburi et al, using a training programme similar to that used in the unassisted arm of the current study, described training intensities approaching $100 \%$ Wpeak in 25 patients with severe COPD (mean FEV $36 \%$ predicted) during the last week of training. ${ }^{8}$ Compared with that study, the patients in the present trial had significantly worse disease (mean $\mathrm{FEV}, 27 \%$ predicted) yet training work rates are comparable. The training intensity achieved continued to increase during the last weeks of the study so it is possible that greater training effects may have been seen had the programme continued for longer. Indeed, the optimal length of training for patients with severe COPD has not been established, although a minimum of 4 weeks seems necessary to produce significant changes in exercise capacity. ${ }^{28}$

We have recently shown that exercise induced lactataemia is prolonged in patients using IPS during exhaustive treadmill exercise, ${ }^{12}$ supporting the view that the training stimulus with $\mathrm{PAV}$ is increased.

The strong correlation between $\left[\mathrm{La}^{+}\right] \mathrm{max}$ and $\Delta \mathrm{L}$ within the assisted group is similar to that reported by Casaburi et al in patients with moderately severe COPD, especially those who underwent a high intensity training programme. ${ }^{7}$ A further study by the same investigators in patients with more severe COPD failed to demonstrate a significant $\Delta \mathrm{L}$ despite a high intensity training programme and impressive improvements in exercise capacity. ${ }^{8}$ One possible explanation for the difference in $\Delta \mathrm{L}$ between the two groups in this study is that PAV allowed subjects to use the full flow-volume envelope, enabling them to perform similarly to the patients with moderate COPD in the study by Casaburi et al.

In this study we used PAV rather than conventional IPS to provide ventilatory assistance. The advantages of this approach were twofold; PAV is considered more comfortable and therefore more acceptable to patients with COPD ${ }^{14}$ and, moreover, as the magnitude of assist changes with demand, ${ }^{13} \mathrm{PAV}$ is able to respond to the increase in respiratory effort seen during exercise.

This study demonstrates a beneficial effect of ventilatory assistance when used by patients with severe COPD during exercise training. Furthermore, the results suggest that a true physiological training effect may be achieved and it would be interesting to demonstrate, using limb muscle biopsy specimens, appropriate changes in capillary density, mitochondria, and oxidative enzymes. The relationship between physiological improvement and functional capacity was not assessed in this study but is an area which requires further research.

Because of the selective nature of the study population, the application of PAV during training may have a limited role in the general population of patients with COPD, many of whom have significant co-morbidity. Nevertheless, the subjects did have severe disease and were recruited from general respiratory medicine clinics, supporting the view that, with careful selection, some patients could benefit from this technique.

We conclude that ventilatory assistance using PAV in patients with severe COPD undergoing a rigorous cycle 
exercise programme leads to increased training intensities which result in improvements in exercise performance with some evidence of true physiological adaptation. This approach may potentially be useful in pulmonary rehabilitation programmes, although further studies are needed to confirm this.

\section{ACKNOWLEDGEMENT}

Peter Hawkins is funded by grant (F97/1) from the British Lung Foundation. Dimitra Nikoletou is funded by Respironics Inc who also provided the ventilators used in this study.

\section{Authors' affiliations}

P Hawkins, L C Johnson, D Nikoletou, J Moxham, Department of Respiratory Medicine \& Allergy, Guy's, King's and St Thomas' School of Medicine, King's College Hospital, London, UK

R Sherwood, Department of Clinical Biochemistry, Guy's, King's and St Thomas' School of Medicine, King's College Hospital, London, UK C-H Hamnegård, Department of Pulmonary Medicine, Sahlgrenska University Hospital, Gothenburg, Sweden

M I Polkey, Respiratory Muscle Laboratory, Royal Brompton Hospital, London, UK

\section{REFERENCES}

1 Killian KJ, Leblanc P, Martin DH, et al. Exercise capacity and ventilatory, circulatory, and symptom limitation in patients with chronic airflow limitation. Am Rev Respir Dis 1992;146:935-40.

2 Belman MJ. Factors limiting exercise performance in lung disease. Ventilatory insufficiency. Chest 1992;101:253-254s.

3 Maltais F, Sullivan M, LeBlanc $P$, et al. Altered expression of myosin heavy chain in the vastus lateralis muscle in patients with COPD. Eu Respir J 1999:13:850-4

4 Maltais F, Simard AA, Simard C, et al. Oxidative capacity of the skeletal muscle and lactic acid kinetics during exercise in normal subjects and in patients with COPD. Am J Respir Crit Care Med

1996:153:288-93.

5 Goldstein RS, Gort EH, Stubbing D, et al. Randomised controlled trial of respiratory rehabilitation. Lancet 1994;344:1394-7.

6 Griffiths T, Burr M, Campbell I, et al. Results at 1 year of outpatient multidisciplinary pulmonary rehabilitation: a randomised controlled trial. Lancet 2000;355:362-8.

7 Casaburi $\mathbf{R}$, Patessio A, Loli $F$, et al. Reductions in exercise lactic acidosis and ventilation as a result of exercise training in patients with obstructive lung disease. Am Rev Respir Dis 1991;143:9-18.

8 Casaburi R, Porszasz J, Burns MR, et al. Physiologic benefits of exercise training in rehabilitation of patients with severe chronic obstructive pulmonary disease. Am J Respir Crit Care Med 1997;155:1541-51.

9 Maltais F, Reissmann H, Gottfried SB. Pressure support reduces inspiratory effort and dyspnoea during exercise in chronic airflow obstruction. Am J Respir Crit Care Med 1995;151:1027-33.

10 Keilty SE, Ponte J, Fleming TA, et al. Effect of inspiratory pressure support on exercise tolerance and breathlessness in patients with severe stable chronic obstructive pulmonary disease. Thorax 1994;49:990-4.
11 Polkey MI, Kyroussis D, Mills GH, et al. Inspiratory pressure support reduces slowing of inspiratory muscle relaxation rate during exhaustive treadmill walking in severe COPD. Am J Respir Crit Care Med 1996;154:1146-50.

12 Polkey MI, Hawkins P, Kyroussis D, et al. Inspiratory pressure support prolongs exercise induced lactataemia in severe COPD. Thorax 2000;55:547-9.

13 Younes M. Proportional assist ventilation, a new approach to ventilatory support. Theory. Am Rev Respir Dis 1992;145:1 14-20.

14 Stell IM, Ellum SG, Moxham J. Effects of mask type, and method of ventilator triggering on tolerability on non-invasive ventilation (NIPPV): In COPD After Exercise. Am J Respir Crit Care Med 2000;161s:A554.

15 Dolmage TE, Goldstein RS. Proportional assist ventilation and exercise tolerance in subjects with COPD. Chest 1997;111:948-54.

16 Borg GAV. Psychophysical basis of perceived exertion. Med Sci Sports Exerc 1982;14:377-81.

17 Bianchi L, Foglio K, Pagani $M$, et al. Effects of proportional assis ventilation on exercise tolerance in COPD patients with chronic hypercapnia. Eur Respir J 1998;11:422-7.

18 Quanjer P. Standardised lung function testing. Report Working Party for the European Community for Steel and Coal. Bull Eur Physiopathol Respir $1983 ; 19$

19 Forster HV, Dempsey JA, Thomson J, et al. Estimation of arterial $\mathrm{PO}_{2}$, $\mathrm{PCO}_{2}, \mathrm{pH}$, and lactate from arterialized venous blood. J Appl Physiol 1972;32:134-7.

20 Clark TJH, Freedman S, Campbell EJM, et al. The ventilatory capacity of patients with chronic airways obstruction. Clin Sci 1969;36:307-16.

21 Polese G, Vitacca M, Bianchi L, et al. Nasal proportional assist ventilation unloads the inspiratory muscles of stable patients with hypercapnia due to COPD. Eur Respir J 2000;16:491-8.

22 Hernandez P, Maltais F, Gursahaney A, et al. Proportional assist ventilation may improve exercise performance in severe chronic obstructive pulmonary disease. J Cardiopulm Rehab 2001;21:135-42.

23 Richardson S, Sheldon J, Poole DC, et al. Evidence of skeletal muscle metabolic reserve during whole body exercise in patients with chronic obstructive pulmonary disease. Am J Respir Crit Care Med 1999; 159:881-5

24 Harms CA, Babcock MA, McClaran SR, et al. Respiratory muscle work compromises leg blood flow during maximal exercise. J Appl Physiol 1997:82:1573-83

25 Maltais F, Jobin J, Sullivan M, et al. Metabolic and hemodynamic responses of lower limb during exercise in patients with COPD. J Appl Physiol 1998;84:1573-80.

26 Casaburi R. Principles of exercise training. Chest 1992;101:263-7S.

27 Saltin B, Gollnick PD. Skeletal muscle adaptability: significance for metabolism and performance. In: The handbook of physiology. American Physiology Society, 1982: 555-631.

28 Maltais $F$, LeBlanc $P$, Simard $C$, et al. Skeletal muscle adaptation to endurance training in patients with chronic obstructive pulmonary disease. Am J Respir Crit Care Med 1996;154:442-7.

29 Sala EJR, Marrades RM, Alonso J, et al. Effects of endurance training on skeletal muscle bioenergetics in chronic obstructive pulmonary disease. Am J Respir Crit Care Med 1999;159:1726-34.

30 Jones N. Clinical exercise testing. 4th ed. Philadelphia: W B Saunders, 1997.

31 Maltais $\mathbf{F}$, LeBlanc $P$, Jobin J, et al. Intensity of training and physiologic adaptation in patients with chronic obstructive pulmonary disease. Am J Respir Crit Care Med 1997;155:555-61. 